\title{
Application of Ultrasound-Assisted Extraction and Heating Combined With ICP-OES for Coal Sample Analysis
}

\author{
Suzana Frighetto Ferrarini and Sandra Maria Maia* \\ Instituto de Química, Universidade Federal do Rio Grande do Sul, \\ Av. Bento Gonçalves, 9500, Caixa Postal 15003, CEP 91501-970 Porto Alegre, RS, Brazil
}

\section{INTRODUCTION}

Coal plays an important role as a source of energy for heating, cooking, steel production, including the ashes produced during its combustion which can be employed for cement production. The different use of electricity by the public and in industry requires a great quantity of coal resulting in the release of pollutants to the atmosphere and ashes into the environment (1). Environmental problems resulting from coal combustion are due to the mobility (into the air or water) of some of the highly toxic organic and inorganic components (2). In this case, the presence of dangerous trace elements in coal are of grave concern while others are distributed in bottom ash, fly ash, and desulfurization residues (3). Elements of greatest concern include $\mathrm{As}, \mathrm{B}, \mathrm{Cd}, \mathrm{Hg}, \mathrm{Mo}, \mathrm{Pb}$, and $\mathrm{Se}$, while $\mathrm{Cr}, \mathrm{Cu}, \mathrm{Ni}, \mathrm{V}$, and $\mathrm{Zn}$ can be considered of moderate concern (4). For instance, it is well known that arsenic affects the gastrointestinal tract, circulatory system, liver, kidney, and skin (5). For these reasons, research involving coal and its ashes is increasing (6) as well the development of rapid and accurate methods for trace element quantification.

Analytical techniques such as atomic absorption spectrometry (AAS) with different atomizers or sample introduction systems (7-10), inductively coupled plasma optical emission spectrometry (ICP-OES) $(3,11)$, and inductively coupled

*Corressponding author

E-mail: sandramaia@iq.ufrgs.br

Fax: 555133087304

\section{ABSTRACT}

The aim of this work was the development of an analytical methodology for the extraction of $\mathrm{As}, \mathrm{Co}, \mathrm{Cu}, \mathrm{Mn}, \mathrm{Ni}, \mathrm{Pb}, \mathrm{V}$, and Zn from coal samples using nitric acid medium, ultrasound, heating, and determination by ICPOES. For this purpose, the ground samples (particle size $\leq 45 \mu \mathrm{m}$ ) were extracted in concentrated $\mathrm{HNO}_{3}$ during 2 hours at $80{ }^{\circ} \mathrm{C}$, left standing for 24 hours, and brought to volume with deionized water $(30 \% \mathrm{v} / \mathrm{v}$ $\mathrm{HNO}_{3}$ ). The suspensions were homogenized by an ultrasonic probe $(70 \mathrm{~W}, 60$ seconds) and the volume brought to a final concentration of $15 \%(\mathrm{v} / \mathrm{v})$ $\mathrm{HNO}_{3}$. Afterwards, the samples were centrifuged at $3000 \mathrm{rpm}$ for 30 minutes and the elements determined in the supernatant.

The developed methodology was applied to the analysis of four coal standard reference materials (SARM 18, SARM 19, SARM 20, and SRM 1635) and three coals collected from different power plants located in the South of Brazil (states of the Rio Grande do Sul, Santa Catarina, and Paraná).

For $\mathrm{As}, \mathrm{Co}, \mathrm{Cu}, \mathrm{Mn}, \mathrm{Ni}, \mathrm{Pb}$ and $\mathrm{Zn}$, there was good agreement between the certified or informed values and those obtained by ultrasound-assisted acid extraction and heating. The exception was for the $\mathrm{V}$ determination in three samples (SARM 18, SARM 19, and SARM 20). Accurate results for $\mathrm{V}$ were only obtained when the coal samples were decomposed by microwave digestion. plasma mass spectrometry (ICP-MS) (11-12) are being used for metal quantification in coal. The ICP-OES and ICP-MS techniques have been used in large scale due to their multi-elemental characteristics, high sensitivity, precision, accuracy, and speed. In addition, these techniques can be coupled to various sampling introduction systems (13-14) allowing their application to the analysis of several kinds of samples (15-16). When the conventional pneumatic nebulization introduction system is employed, a complete dissolution of the sample is required. For coal samples, the most traditional dissolution methods are wet digestion (11), dry ashing (17), and fusion (18). Nevertheless, these methods are associated with disadvantages such as use of reagents, vessel contamination, and volatile elements lost due to the long time required for sample preparation and the high temperatures used during the process.

Nowadays, microwave acid decomposition is being extensively used for dissolution of different kinds of samples, including coal (3, 11-12). This process is considered safe and rapid and less prone to contamination (11); however, only a small sample amount can be used (19). Since coal has a complex matrix, various acids and acid mixtures $\left(\mathrm{HNO}_{3}, \mathrm{HClO}_{4}, \mathrm{HCl}, \mathrm{H}_{2} \mathrm{SO}_{4}\right.$, $\mathrm{H}_{3} \mathrm{BO}_{3}$, and $\mathrm{H}_{2} \mathrm{O}_{2}$ ) are used for its dissolution. But there are some restrictions to consider in their use as well as safety considerations $\left(\mathrm{HClO}_{4}\right.$ and $\left.\mathrm{HF}\right)$, negative effects on instrument parts ( $\mathrm{HF}$ and $\mathrm{H}_{2} \mathrm{SO}_{4}$ ), matrix effects $\left(\mathrm{H}_{2} \mathrm{SO}_{4}\right.$ and $\left.\mathrm{H}_{3} \mathrm{BO}_{3}\right)$, and spectral interferences in ICP$\mathrm{MS}\left(\mathrm{H}_{2} \mathrm{SO}_{4}, \mathrm{HClO}_{4}\right.$, and $\left.\mathrm{HCl}\right)$ (12). 
Alternative techniques of sample pre-treatment for coal analysis that have been applied with ICP-OES and/or ICP-MS (20) include slurry nebulization, electrothermal vaporization (21-22), and laser ablation (11). These techniques offer several advantages, including simpler sample preparation with lower risk of contamination and analyte losses (11). Parry and Ebdon (20) obtained quantitative results for major and trace constituents in coal by slurry nebulization ICP-OES/ICP-MS using a high solid content nebulizer. But poor results were obtained for $U$ by ICP-MS, probably due to contamination. Moreover, the time required to reduce the size of the coal particles to $<10 \mu \mathrm{m}$ was around 12 hours. The advantages of slurry sampling were demonstrated in several studies (23-31) for a variety of samples. However, it was found that, in general, the particle size must be small, the slurry must be homogeneous and relatively concentrated, and a partial extraction of the analyte into the liquid phase may be of importance.

For overcoming these drawbacks, ultrasound-assisted leaching in acid medium appears as an alternate and effective way of extracting a number of analytes from different types of samples (32-35), including coal. It should be pointed out that with quantitative extraction, only the supernatant liquid can be introduced into the equipment and it is not necessary to use special introduction devices. In addition, the calibration against aqueous solutions becomes feasible, simplifying the analytical procedure. Maia et al. (22) performed quantitative recovery of $\mathrm{Pb}$ (but not of $\mathrm{Cd}$ and $\mathrm{Tl}$ ) from coal samples using an ultrasonic cleaner bath for 120 minutes and then a water bath at $60{ }^{\circ} \mathrm{C}$ for 120 minutes. In contrast, Ribeiro et al. (36) reported quantitative extraction of $\mathrm{Hg}$ from coal samples with the use of a similar device for sonication. In that study, the powdered samples were prepared in acidic medium, placed in an ultrasonic bath for 30 minutes, and left standing at room temperature for 48 hours. Then they were submitted to the ultrasonic bath again for another 30 minutes. Collasiol et al. (37) also obtained good results for $\mathrm{Hg}$ determination in marine sediment when acid extraction was employed. In that work, $\mathrm{Hg}$ was quantitatively leached out into 30\% (v/v) $\mathrm{HNO}_{3}$, assisted by ultrasonic irradiation (during 90-120 s, $70 \mathrm{~W}$ ), and a sample particle size of $\leq 120 \mu \mathrm{m}$. Ilander and Väisänem (38) reported recovery rates of over $92 \%$ for $\mathrm{Cu}, \mathrm{Ni}, \mathrm{Pb}, \mathrm{V}$, and $\mathrm{Zn}$ in coal fly ash samples using ultrasound-assisted two-step digestion: digestion solutions of $6 \mathrm{~mL}$ of $\mathrm{HNO}_{3}$ (step 1) and $3 \mathrm{~mL}$ of $\mathrm{HNO}_{3}+$ $3 \mathrm{~mL}$ of HF (step 2), followed by ICP-OES determination. For the same kind of sample, Pontes et al. (39) proposed a digestion procedure consisting in the sonication of the sample with $\mathrm{HF}$ and aqua regia at $80{ }^{\circ} \mathrm{C}$ for 30 minutes, elimination of the fluorides by heating until dryness ( 1 hour), and dissolution of the residue with $\mathrm{HNO}_{3}$. According to the authors, the results obtained for for $\mathrm{Co}, \mathrm{Fe}, \mathrm{Mn}, \mathrm{Ni}$, Ti, V, and $\mathrm{Zn}$ were in agreement with reference values, except for $\mathrm{Cr}$ and $\mathrm{Cu}$.

The aim of this work was the development of an analytical methodology for the extraction of As, $\mathrm{Co}, \mathrm{Cu}, \mathrm{Mn}, \mathrm{Ni}, \mathrm{Pb}, \mathrm{V}$, and $\mathrm{Zn}$ from coal samples using nitric acid medium, ultrasound, heating, and their determination by ICP-OES.

The ultrasound-assisted extraction process was fully characterized by optimization of variables such as ultrasound power, sonication time, and particle size. The elements of interest were determined directly in the supernatant to circumvent a number of variables that influence the accuracy and precision in slurry sampling, such as the presence of wetting agents, particle size, and density of the solid samples (35). In addition, external calibration could be used. The results obtained with the proposed methodology were compared with those obtained with microwave decomposition.

\section{EXPERIMENTAL}

\section{Instrumentation}

ICP-OES analysis was performed using the Optima ${ }^{\mathrm{TM}} 2000 \mathrm{DV}$ instrument (PerkinElmer, Inc., Shelton, CT, USA). This spectrometer has an axial/radial plasma configuration with a GemCone ${ }^{\circledR}$ nebulizer coupled to a double-pass Scott-type spray chamber. The instrumental conditions were optimized to obtain sufficient sensitivity and precision. The eight trace elements determined and their wavelengths (see Table I) were chosen according to preliminary studies made for these elements using ICP-OES (15). Argon with a purity of $99.996 \%$ (White Martins, São Paulo, Brazil) was used. The instrumental parameters are listed in Table I.

An ultrasonic processor (Unique, Brazil), equipped with a 4-mm diameter titanium tip, was used. Ultrasonic vibration at the probe tip was fixed at any desired power level using a power setting in the $20-100 \%$ range. The ultrasonic processor was enclosed inside a sound-proof chamber during operation. The time of sonication could be increased in steps of 5 seconds each of the intended period of sonication. A model BE-4004 centrifuge (BIOENG, Brazil) was used to centrifuge the suspensions, and a waterbath (De Leo, Brazil) was employed for heating the samples. For microwave dissolution, a model MDS-2000 microwave system (CEM Corp., Matthews, NC, USA), equipped with 12 perfluoroalcoxy (PFA) vessels with safety rupture membranes (maximum operating power $630 \mathrm{~W}$ ), was used. The vessels are located on a rotating turntable to ensure even sample 
heating. Before use and between each batch of samples, the PFA (perfluoroalcoxy) vessels were thoroughly acid-cleaned and then rinsed with deionized water.

\section{Reagents and Standard Solutions}

All chemicals were of analytical reagent grade. Nitric acid, hydrofluoric acid, and hydrogen peroxide (Merck, Darmstadt, Germany) were used. Nitric acid used for sample preparation and calibration solutions was further purified by subboiling distillation using a quartz still (Kürner Analysentechnik, Rosenheim, Germany). The water was purified in a Milli-Q ${ }^{\mathrm{TM}}$ system (Millipore, Bedford, MA, USA), resulting in water with a resistivity of $18.2 \mathrm{M} \Omega \mathrm{cm}$. The glassware materials and polypropylene flasks were kept in $10 \%(\mathrm{v} / \mathrm{v}) \mathrm{HNO}_{3}$ solution and rinsed abundantly with deionized water.

Analytical solutions for As and $\mathrm{Cu}$ (10 to $240 \mu \mathrm{g} \mathrm{L}^{-1}$ ), Co (2.5 to $\left.80 \mu \mathrm{g} \mathrm{L}^{-1}\right), \mathrm{Mn}$ and $\mathrm{Zn}$ (25 to $600 \mu \mathrm{g} \mathrm{L}^{-1}$ ), Ni (10 to $180 \mu \mathrm{g} \mathrm{L}^{-1}$, $\mathrm{Pb}$ and $\mathrm{V}$ (10 to $320 \mu \mathrm{g} \mathrm{L}^{-1}$ ) were prepared by appropriate dilution of $1000 \mathrm{mg} \mathrm{L}^{-1}$ single-element stock solutions Titrisol ${ }^{\circledR}$ (Merck). The $\mathrm{HNO}_{3}$ concentration in the calibration solutions was varied in order to match that of the sample solution.

The following certified reference materials were investigated: SARM 18 Coal, Witbank, SARM 19 Coal, O.F.S. and SARM 20 Coal, Sasolburg (SA Bureau of Standards, Pretoria, South Africa), SRM 1635 Trace Elements in Coal, Subbituminous, (National Institute of Standards and Technology, Gaithersburg, MD, USA), and SRM 1632a Trace Elements in Coal, Bituminous, (National Bureau of Standards, Washington, DC, USA). The real coal samples analyzed in this work were obtained from mines in three different states of southern Brazil: Rio Grande do Sul, Santa Catarina, and Paraná.

\section{Sample Preparation for Preliminary Optimizations and Analyses}

For investigation of the influence of the plasma power, nebulizer, and auxiliary gas flow rates on the analyte signal intensity, the slurries were prepared by mixing around

TABLE I

Instrumental Parameters for ICP-OES

\begin{tabular}{ll}
\hline RF Power & $1400 \mathrm{~W}$ \\
Plasma Gas Flow & $15 \mathrm{~L} \mathrm{~min}^{-1}$ \\
Auxiliary Gas Flow & $0.2 \mathrm{~L} \mathrm{~min}^{-1}$ (As, Co, Cu, Mn, Ni, Pb, V and Zn) \\
Nebulizer Flow & $0.6 \mathrm{~L} \mathrm{~min}^{-1}$ (As and Pb), \\
& $0.7 \mathrm{~L} \mathrm{~min}^{-1}(\mathrm{Co}, \mathrm{Mn}, \mathrm{Ni}, \mathrm{V}$ and $\mathrm{Zn})$, \\
& $0.9 \mathrm{~L} \mathrm{~min}^{-1}(\mathrm{Cu})$ \\
Plasma View & Axial \\
Nebulizer & GemCone ${ }^{\circledR}$ \\
Spray chamber & Scott Ryton ${ }^{\circledR}$ \\
Sample flow rate & $1.5 \mathrm{~mL} \mathrm{~min}^{-1}$ \\
Replicates & 2 \\
Background correction & 2 points \\
Wavelengths & As $(188.979 \mathrm{~nm}), \mathrm{Co}(231.160 \mathrm{~nm})$, \\
& Cu $(327.393 \mathrm{~nm}), \mathrm{Mn}(257.610 \mathrm{~nm})$, \\
& $\mathrm{Ni}(231.604 \mathrm{~nm}), \mathrm{Pb}(220.353 \mathrm{~nm})$, \\
& V $(292.464 \mathrm{~nm})$, and $\mathrm{Zn}(213.857 \mathrm{~nm})$ \\
\hline
\end{tabular}

a Optimized parameters.

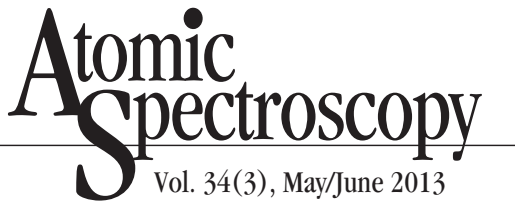

$0.2 \mathrm{~g}$ of the coal SARM $20(<106 \mu \mathrm{m})$, with $4.5 \mathrm{~mL}$ of concentrated nitric acid into screw-capped 50-mL polypropylene flasks. The mixture was then left standing for $45 \mathrm{~min}$ utes and made up to $15-\mathrm{mL}$ volume, obtaining a concentration of $30 \%$ (v/v) in $\mathrm{HNO}_{3}$. The suspensions were homogenized by an ultrasonic probe ( $50 \mathrm{~W}, 60$ seconds), then the volume was made up to $30 \mathrm{~mL}$, resulting in a final concentration of $15 \%(\mathrm{v} / \mathrm{v})$ in $\mathrm{HNO}_{3}$. The choice of these conditions was based on a previous work (40). The final slurry was centrifuged for 30 minutes at $3000 \mathrm{rpm}$. For all analyses, the slurries were prepared in triplicate. For the measurements, the aliquots were taken from the supernatant.

For the optimization study of the ultrasonic probe conditions, the sonication power and sonication time were varied and the slurries prepared with SARM 19 Coal, used as received (particle size $<106 \mu \mathrm{m}$ ), following the same sample preparation as mentioned above.

In order to study the influence of extraction time, approximately $0.2 \mathrm{~g}$ of SARM 19 Coal was mixed with concentrated nitric acid ( 4.5 $\mathrm{mL})$, and rest times of 45 minutes, 15,24 , and 48 hours were established for extraction. Afterwards, the sample preparation was performed as described above. For this investigation, the optimized conditions obtained for sonication power and sonication time were $70 \mathrm{~W}$ and 60 seconds, respectively.

The SRM 1632a Coal (particle size $<250 \mu \mathrm{m}$ ) was ground in an agate mortar and passed through $\leq 45 \mu \mathrm{m}, \leq 121 \mu \mathrm{m}, \leq 150 \mu \mathrm{m}$, and $\leq 250 \mu \mathrm{m}$ polyester sieves to investigate the effect of particle size on the extraction of the elements. The optimized conditions of rest time of 24 hours in $\mathrm{HNO}_{3}$, sonication power of $70 \mathrm{~W}$, and sonication time of 60 seconds were used. The sample preparation procedure was as mentioned above. 
For analysis of the coal reference materials and the coal real samples (particle size $<450 \mu \mathrm{m}$ ), all coal samples were further ground and sieved to a particle size of $\leq 45 \mu \mathrm{m}$, mixed with $4.5 \mathrm{~mL}$ concentrated nitric acid, then kept in a waterbath for two hours at $80^{\circ} \mathrm{C}$. The slurries were left standing for 24 hours and submitted to the procedure described before.

\section{Microwave-Assisted Acid Digestion Procedure}

For microwave dissolution, a sample mass of about $0.15 \mathrm{~g}$ and a reagent mixture $\left(5 \mathrm{~mL} \mathrm{HNO}_{3}+\right.$ $1 \mathrm{~mL} \mathrm{HF}+2 \mathrm{~mL} \mathrm{H}_{2} \mathrm{O}_{2}$ ) were used (11). The weighed coal samples were transferred to PFA vessels, and nitric acid $(5 \mathrm{~mL})$ was added. The vessels were left standing (15 minutes) and then submitted to the first stage of the microwave decomposition program as recommended by the manufacturer (Table II). After appropriate cooling, the vessels were opened and the other reagents added. The vessels were left standing for 1 hour and returned to the microwave for the second stage of the program. After cooling, the resulting solutions were transferred to polypropylene flasks and brought to 25 -mL volume with deionized water.
TABLE II Microwave Decomposition Program

\begin{tabular}{lrrr}
\hline Stage 1 & & & \\
\hline Steps & 1 & 2 & 3 \\
Power (\%) & 70 & 70 & 70 \\
Time (min) & 15 & 15 & 15 \\
Cooling (min) & 5 & 5 & 5 \\
\hline Stage $2^{\mathrm{b}}$ & & & \\
\hline Steps & 1 & 2 & 3 \\
Power (\%) & 70 & 70 & 70 \\
Time (min) & 15 & 15 & 20 \\
Cooling (min) & 5 & 5 & 15 \\
\hline $\begin{array}{l}\text { a Related to a total power of } 630 \mathrm{~W} \\
\text { and six vessels. } \\
\text { b Addition of : } \mathrm{H}_{2} \mathrm{O}_{2}+\mathrm{HF}\end{array}$
\end{tabular}

\section{RESULTS AND DISCUSSION}

\section{Optimization of ICP-OES Instrumental Parameters}

Initially, the plasma power, nebulizer, and auxiliary gas flow rates were optimized in order to obtain the best sensitivity for $\mathrm{As}, \mathrm{Co}, \mathrm{Cu}$, $\mathrm{Mn}, \mathrm{Ni}, \mathrm{Pb}, \mathrm{V}$ and $\mathrm{Zn}$, measured together in the SARM 20 Coal sample. The signal intensities of the elements present in the supernatant of the suspensions were measured and the results are shown in Fig- ures 1, 2, and 3. According to Figure 1 , the highest intensities of the emission signals for the elements were obtained when the power was set at $1500 \mathrm{~W}$, except for As. Although it was expected that the higher RF generator power should benefit As due to its high ionization potential, experimentally the power of $1400 \mathrm{~W}$ produced the highest signal, even though the experiment was repeated twice. Therefore, $1400 \mathrm{~W}$ was adopted in order to obtain the highest signal for As, present at low concentrations in the sample. As can be seen in Figure 1, for the majority of the elements, the signal intensities were higher with an increase in power. This behavior may be related to the fact that a hotter plasma is obtained when the power is higher. Consequently, a great number of atoms and ions are generated resulting in an enhancement of element emissions (16). With regard to Figure 2 it can be seen that the analyte signal intensity increases as the nebulizer gas flow rate increases up to a maximum, then decreases at higher flow rates. Higher rates may cool the plasma, thus reducing the quantity of atoms and ionized species and also the residence time in the plasma (41).

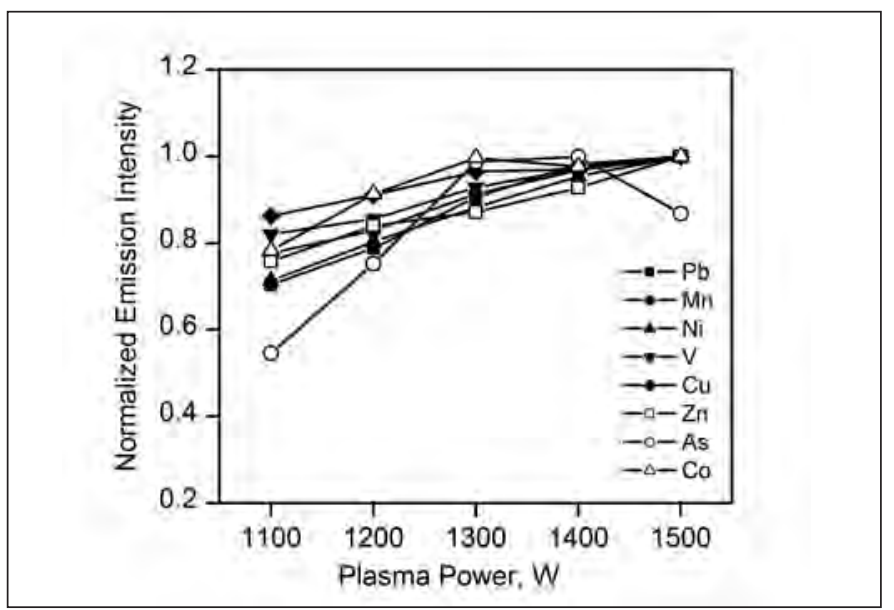

Fig. 1. Influence of the plasma power in the emission intensity for As, Co, Cu, Mn, Ni, Pb, V, and $\mathrm{Zn}$ in the Certified Reference Material SARM 20.

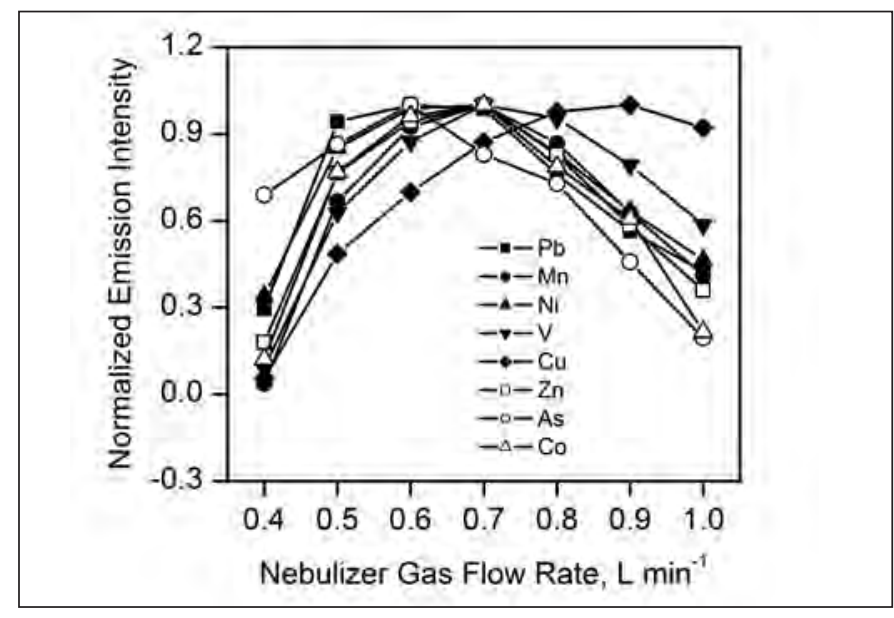

Fig. 2. Influence of the nebulizer gas flow in the emission intensity for $\mathrm{As}, \mathrm{Co}, \mathrm{Cu}, \mathrm{Mn}, \mathrm{Ni}, \mathrm{Pb}, \mathrm{V}$ and $\mathrm{Zn}$ in the Certified Reference Material SARM 20. 


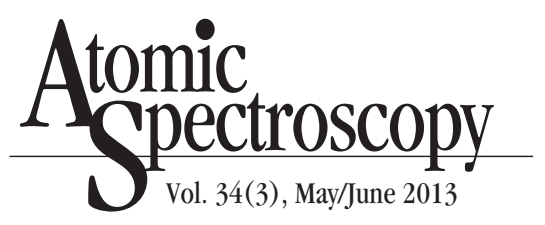

For As and $\mathrm{Pb}$, the maximum flow rate was $0.6 \mathrm{~L} \mathrm{~min}^{-1}$, for $\mathrm{Co}, \mathrm{Mn}, \mathrm{Ni}$, $\mathrm{V}$, and $\mathrm{Zn}$ it was $0.7 \mathrm{~L} \mathrm{~min}^{-1}$ and for $\mathrm{Cu}, 0.9 \mathrm{~L} \mathrm{~min}^{-1}$. These values were chosen for the next optimizations. As shown in Figure 3, an auxiliary gas flow rate of $0.2 \mathrm{~L} \mathrm{~min}^{-1}$ was adequate for all of the elements, except for $\mathrm{Pb}$. A flow rate of $0.2 \mathrm{~L} \mathrm{~min}^{-1}$ was set for all subsequent measurements.

\section{Optimization of Sonication Power and Sonication Time}

An optimization study was carried out for investigating the conditions of sonication power and time that would give greater extraction of the elements studied. For these experiments, the SARM 19 Coal sample was employed. Figure 4 shows that $70 \mathrm{~W}$ promoted higher signal intensities for $\mathrm{As}, \mathrm{Cu}, \mathrm{Ni}$, and $\mathrm{Zn}$. Additionally, during the experiment it was observed that power values higher than $70 \mathrm{~W}$ provoked an increase in temperature of the

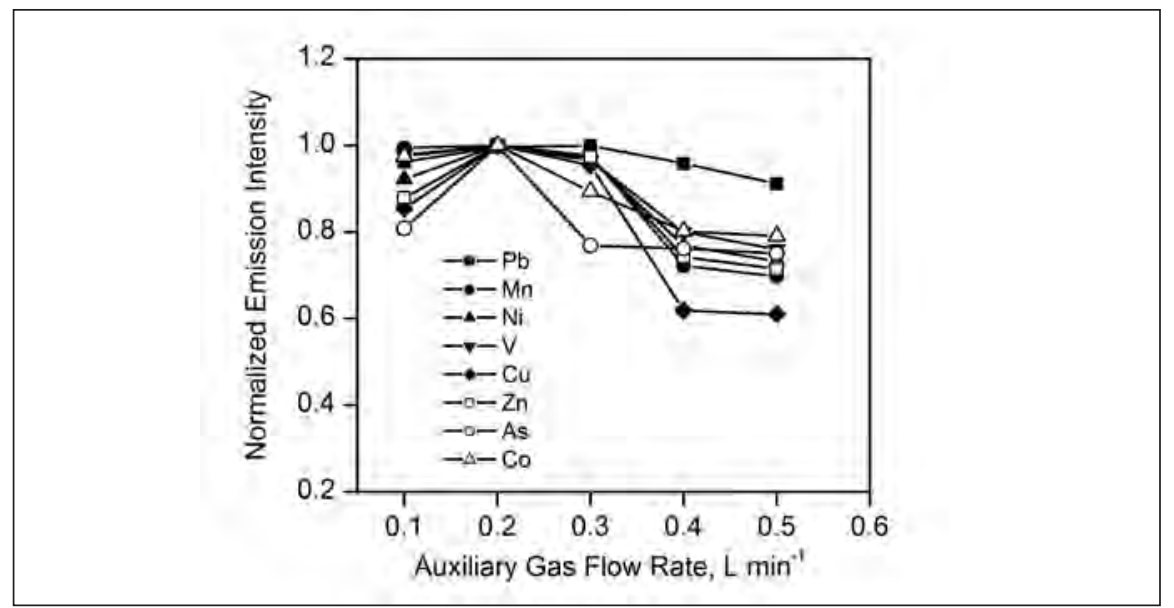

Fig. 3. Influence of the auxiliary gas flow in the emission intensity for As, Co, Cu, $M n, N i, P b, V$ and $\mathrm{Zn}$ in the Certified Reference Material SARM 20.

sample flasks. However, considering the complexity of the sample solution as well as the ultrasound effects, it is difficult to state precisely the reason for the signal decrease observed for some elements above $70 \mathrm{~W}$. Although a sonication time (Figure 5) of 60 seconds was not the best condition for all of the elements, the relative standard deviations of the measurements were lower. It was also observed that at longer times the probe interrupted the sonication due to an overheating. Therefore, $70 \mathrm{~W}$ and 60 seconds were established for further investigations in the present work.

\section{Analytical Results}

When the optimized instrumental conditions were applied to the analysis of SARM 19 Coal, no satisfactory results were obtained for all of the elements, showing that 45 minutes in nitric acid was not enough to leach the elements. In an attempt to solve this problem, the influence of different times in nitric was investigated. Hence, times of 45 minutes, 15 hour, 24 hours, and 48 hours were tested. The results are presented in Figure 6. For As and $\mathrm{Pb}, 24$ hours and 48 hours gave

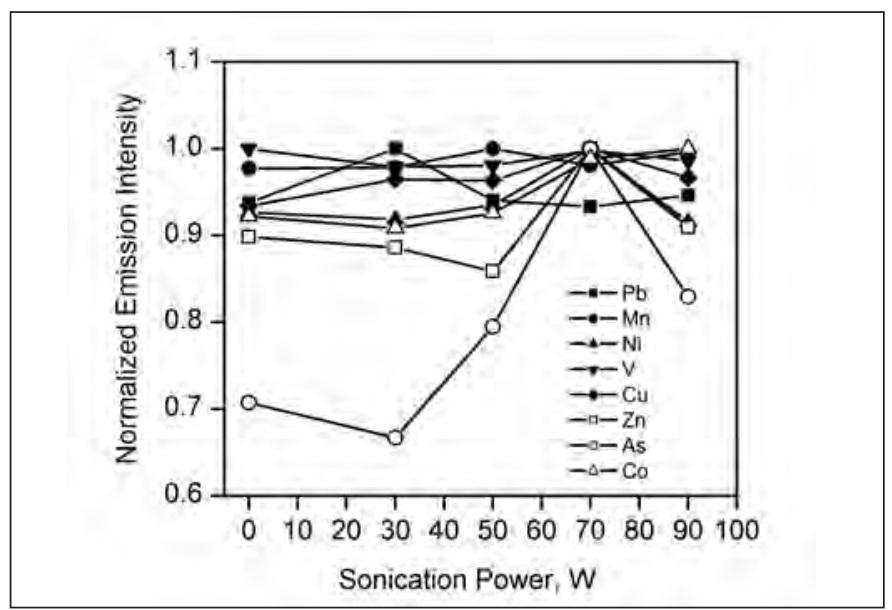

Fig. 4. Effect of the sonication power in the emission intensity for $\mathrm{As}, \mathrm{Co}, \mathrm{Cu}, \mathrm{Mn}, \mathrm{Ni}, \mathrm{Pb}, \mathrm{V}$ and $\mathrm{Zn}$ in the Certified Reference Material SARM 19.

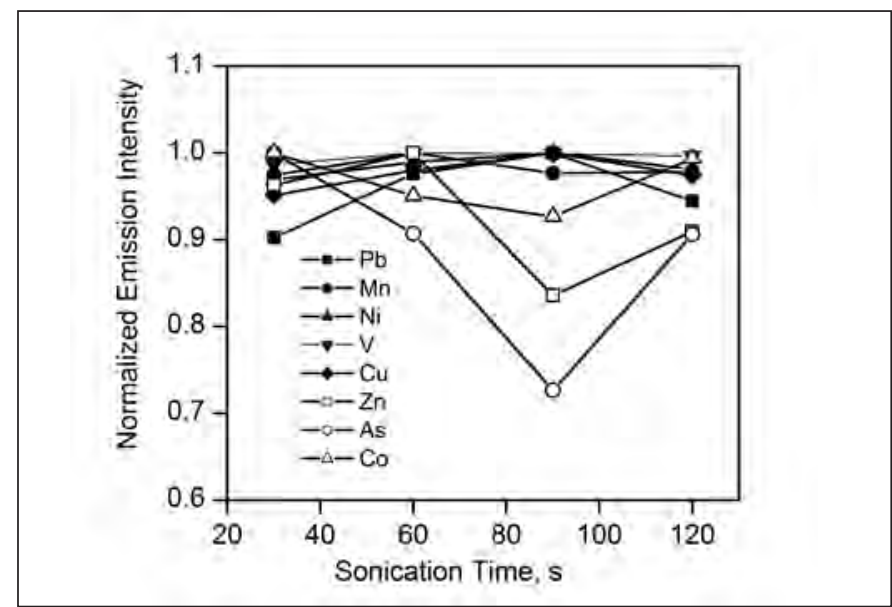

Fig. 5. Effect of the sonication time in the emission intensity for As, Co, Cu, Mn, Ni, Pb, V and $\mathrm{Zn}$ in the Certified Reference Material SARM 19. 
concentration values in the range of the certified values, whereas for $\mathrm{Co}, \mathrm{Cu}, \mathrm{Mn}, \mathrm{Ni}, \mathrm{V}$, and $\mathrm{Zn}$ the concentration values were still low. For additional studies, 24 hours was chosen to improve the solubility of the elements. For this purpose, two new parameters were included: the effect of particle size and heating. First, the effect of particle size was investigated and, therefore, the following particle sizes were evaluated: $\leq 250, \leq 150, \leq 121$, and $\leq 45$ $\mu \mathrm{m}$ for SRM 1632a Coal. Figure 7 shows that the signal emission intensities for the majority of the elements are higher for particle sizes from $\leq 121$ to $\leq 45 \mu \mathrm{m}$. This tendency can be explained by the fact that small particles present a great superficial area, and because of this, the analytes are easily extracted $(22,42)$.

Since the particle size of $\leq 45 \mu \mathrm{m}$ favored more elements, it was chosen for the second step, namely the influence of heating. For this investigation, the ground samples were heated in a waterbath for 2 hours at

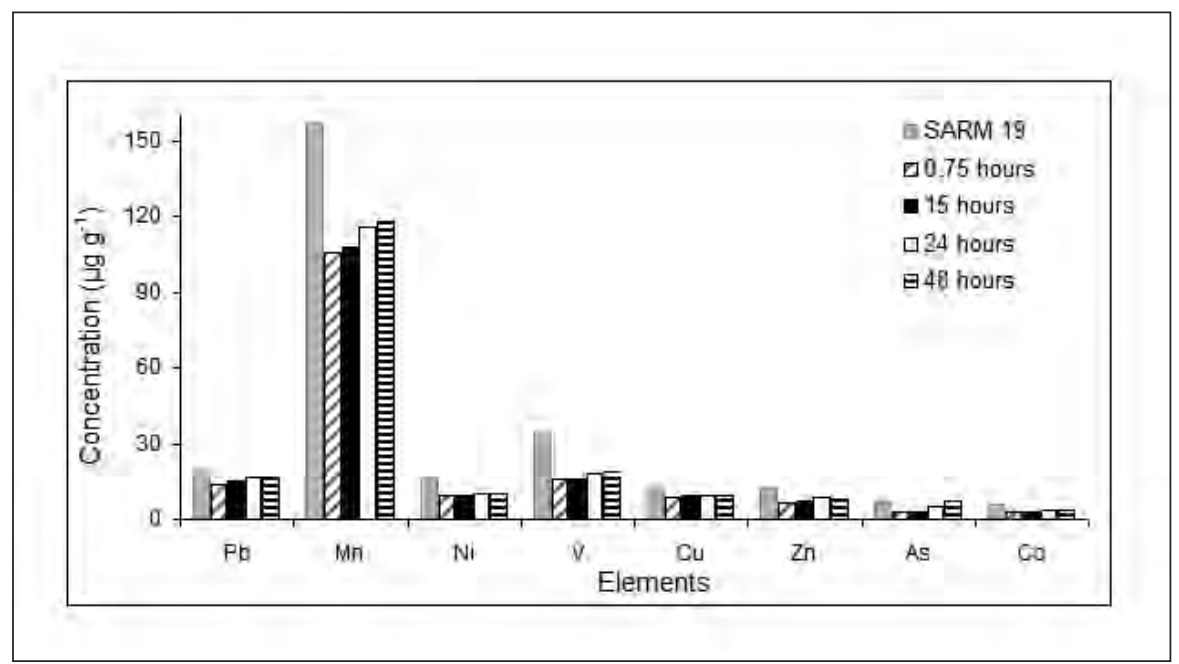

Fig. 6. Influence of the time of extraction in nitric acid for $\mathrm{As}, \mathrm{Co}, \mathrm{Cu}, \mathrm{Mn}, \mathrm{Ni}, \mathrm{Pb}$, $V$ and $\mathrm{Zn}$ in the Certified Reference Material SARM 19.

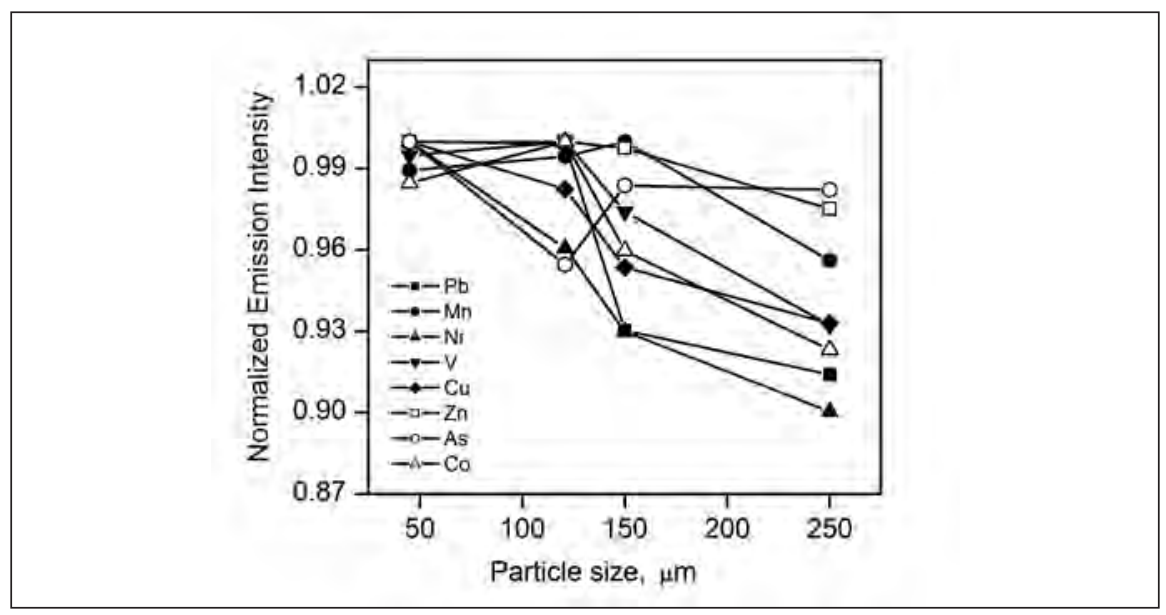

Fig. 7. Influence of the particle size in the extraction of $\mathrm{As}, \mathrm{Co}, \mathrm{Cu}, \mathrm{Mn}, \mathrm{Ni}, \mathrm{Pb}, \mathrm{V}$ and $\mathrm{Zn}$ in the Certified Reference Material SRM 1632a.

$80{ }^{\circ} \mathrm{C}$, left standing for 24 hours, and then submitted to the procedure mentioned above in the experimental section. The results in Table III show that for the majority of elements, there was good agreement between the certified or informed values and the values obtained by hot extraction in nitric acid; the exception was $V$ in SARM 18, SARM 19, and SARM 20 with recoveries of 78,72 , and $62 \%$, respectively. The RDSs varied from 0.4 to $22.8 \%$. It is clear that the heating effectively improved the extraction for the majority of the elements since a further dissolution of the coal samples might be favored with an increase in temperature. The discrepancies between the effectiveness of the extraction of some elements in the different coal samples can be related to the type of coal and also the mode of occurrence of the element in the analyzed material. The coals that have been investigated were in the range of bituminous to sub-bituminous, presenting distinct features in composition which can affect the leaching. In lower rank coals, some inorganic elements tend to be associated to organic matter, but in bituminous coals a great proportion of minor and trace elements are, in general, present with the mineral matter (4). In addition, particular elements may have a strong association with pyrite, whereas others may occur primarily with other mineral phases such as silicates, phosphates, carbonates, and sulphates. The low recoveries for $\mathrm{V}$, for example, can be related to the fact that this element is associated to the clays (silicates) and organic matter (2) which makes its extraction difficult with only $\mathrm{HNO}_{3}$. 


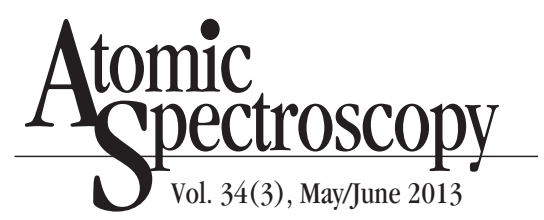

TABLE III

Analysis of Certified Reference Materials SARM 18, SARM 19, SARM 20 and SRM 1635 After Heating + Extraction Assisted by Ultrasound

\begin{tabular}{lll}
\hline \multicolumn{3}{l}{ SARM 18 $\left(\mu \mathrm{g} \mathrm{g}^{-1}\right)$} \\
$\begin{array}{lll}\text { Ele- } \\
\text { ment }\end{array}$ & $\begin{array}{l}\text { Deter- } \\
\text { mined }\end{array}$ & Certified \\
\hline $\mathrm{Pb}$ & $5(1)^{\mathrm{a}}$ & $5^{\mathrm{b}}$ \\
$\mathrm{Mn}$ & $19(3)$ & $22(21-23)^{\mathrm{c}}$ \\
$\mathrm{Ni}$ & $10.3(0.7)$ & $10.8(10.1-11.5)$ \\
$\mathrm{V}$ & $18.0(0.1)$ & $23(21-25)$ \\
$\mathrm{Cu}$ & $5.7(1.3)$ & $5.9(5.2-6.4)$ \\
$\mathrm{Zn}$ & $5.3(0.6)$ & $5.5(5.2-6.8)$ \\
$\mathrm{As}$ & $<\mathrm{LD}$ & $\mathrm{ni}^{\mathrm{d}}$ \\
$\mathrm{Co}$ & $5.5(0.2)$ & $6.7(5.5-7.2)$ \\
\hline
\end{tabular}

\begin{tabular}{lll}
\hline \multicolumn{3}{l}{ SARM 19 $\left(\mu \mathrm{g} \mathrm{g}^{-1}\right)$} \\
\hline $\begin{array}{l}\text { Ele- } \\
\text { ment }\end{array}$ & $\begin{array}{l}\text { Deter- } \\
\text { mined }\end{array}$ & Certified \\
\hline $\mathrm{Pb}$ & $17(1)$ & $20(17-23)$ \\
$\mathrm{Mn}$ & $141(4)$ & $157(143-168)$ \\
$\mathrm{Ni}$ & $14.0(0.1)$ & $16(13-20)$ \\
$\mathrm{V}$ & $25.1(0.1)$ & $35(33-37)$ \\
$\mathrm{Cu}$ & $11(1)$ & $13(11-14)$ \\
$\mathrm{Zn}$ & $13.2(0.4)$ & $12(12-16)$ \\
$\mathrm{As}$ & $8.0(0.2)$ & $7(6-8)$ \\
$\mathrm{Co}$ & $5.1(0.1)$ & $5.6(5-6.6)$
\end{tabular}

\begin{tabular}{lll}
\hline SARM $20\left(\mu \mathrm{g} \mathrm{g}^{-1}\right)$ \\
\hline $\begin{array}{l}\text { Ele- } \\
\text { ment }\end{array}$ & $\begin{array}{l}\text { Deter- } \\
\text { mined }\end{array}$ & Certified \\
\hline $\mathrm{Pb}$ & $23.8(0.4)$ & $26(20-29)$ \\
$\mathrm{Mn}$ & $79(2)$ & $80(77-82)$ \\
$\mathrm{Ni}$ & $24.2(0.4)$ & $25(23-26)$ \\
$\mathrm{V}$ & $29(1)$ & $47(45-50)$ \\
$\mathrm{Cu}$ & $17.3(0.3)$ & $18.0(15-19)$ \\
$\mathrm{Zn}$ & $14(2)$ & $17(14-18)$ \\
$\mathrm{As}$ & $5.4(0.1)$ & $4.7(4.6-6)$ \\
$\mathrm{Co}$ & $7.8(0.2)$ & $8.3(7.6-9)$ \\
\hline SRM & $1635(\mu \mathrm{g} \mathrm{g})$ \\
\hline $\mathrm{Ele}-$ & $\mathrm{Deter}-$ & $\mathrm{Certified}$ \\
$\mathrm{ment}$ & mined & \\
\hline $\mathrm{Pb}$ & $1.9(0.2)$ & $1.9(0.2)^{\mathrm{e}}$ \\
$\mathrm{Mn}$ & $22.5(0.5)$ & $21.4(1.5)$ \\
$\mathrm{Ni}$ & $1.64(0.11)$ & $1.74(0.10)$ \\
$\mathrm{V}$ & $5.0(0.3)$ & $5.2(0.5)$ \\
$\mathrm{Cu}$ & $3.4(0.2)$ & $3.6(0.3)$ \\
$\mathrm{Zn}$ & $5.3(1.0)$ & $4.7(0.5)$ \\
$\mathrm{As}$ & $<\mathrm{LD}$ & $0.42(0.15)$ \\
$\mathrm{Co}$ & $0.63(0.10)$ & $0.65^{\mathrm{b}}$ \\
\hline & &
\end{tabular}

\section{Microwave Digestion}

Microwave digestion was also investigated to evaluate its efficiency in comparison to acid extraction for the element $\mathrm{V}$ whose concentration values were lower than the certified ones. The results in Table IV show that the values obtained for $\mathrm{V}$ were in good agreement with the certified values since the recoveries increased up to $94 \%$ and $98 \%$ in SARM 19 and SARM 20 , respectively. In this case, the elevated temperatures and pressures reached in the microwave vessels, including the acid mixture $\left(\mathrm{HNO}_{3}\right.$ $+\mathrm{H}_{2} \mathrm{O}_{2}+\mathrm{HF}$ ), which favored the decomposition of the organic matter and silicates present in the samples. For the other elements, there were practically no differences between the two methods. In order to confirm statistically the efficiency of acid extraction, the Student's $t$-test for differences in means (43) was applied at the $95 \%$ confidence level, and significant differences were found only for $\mathrm{Cu}$ in SARM 19 and 20, Mn in SRM 1635 , and Ni in SARM 20. It is important to point out that the results obtained for these elements were lower when the samples were decomposed by microwave. Probably some losses occurred during the digestion process or perhaps the power and time of decomposition applied as recommended by the manufacturer was not adequate for bringing these elements into solution.

\section{TABLE III footnotes:}

a The parentheses values are the standard deviation of 3 determinations $(\mathrm{n}=3)$.

b Non-certified value.

${ }^{c}$ The parentheses values are the confidence intervals.

${ }^{\mathrm{d}} \mathrm{ni}=$ non-informed value .

e For this certified reference material, parentheses values are the standard deviation.
TABLE IV

Analysis of Certified Reference Materials SARM 19, SARM 20, and SRM 1635 by ICP-OES After Microwave Decomposition SARM $19\left(\mu \mathrm{g} \mathrm{g}^{-1}\right)$

Element Microwave Certified

\begin{tabular}{lll}
\hline $\mathrm{Pb}$ & $17(1)^{\mathrm{a}}$ & $20(17-23)^{\mathrm{b}}$ \\
$\mathrm{Mn}$ & $144(4)$ & $157(143-168)$ \\
$\mathrm{Ni}$ & $13(1)$ & $16(13-20)$ \\
$\mathrm{V}$ & $33(1)$ & $35(33-37)$ \\
$\mathrm{Cu}$ & $8.1(0.4)$ & $13(11-14)$ \\
$\mathrm{Zn}$ & $13(1)$ & $12(12-16)$ \\
$\mathrm{As}$ & $8(1)$ & $7(6-8)$ \\
$\mathrm{Co}$ & $5.0(0.1)$ & $5.6(5-6.6)$ \\
\hline
\end{tabular}

SARM $20\left(\mu \mathrm{g} \mathrm{g}^{-1}\right)$

\begin{tabular}{lll}
\hline \multicolumn{2}{l}{ Element Microwave } & Certified \\
\hline $\mathrm{Pb}$ & $22(3)$ & $26(20-29)$ \\
$\mathrm{Mn}$ & $82.0(0.4)$ & $80(77-82)$ \\
$\mathrm{Ni}$ & $21(1)$ & $25(23-26)$ \\
$\mathrm{V}$ & $46(1)$ & $47(45-50)$ \\
$\mathrm{Cu}$ & $16.2(0.3)$ & $18.0(15-19)$ \\
$\mathrm{Zn}$ & $15.0(0.3)$ & $17.0(14-18)$ \\
$\mathrm{As}$ & $5.4(0.2)$ & $4.7(4.6-6)$ \\
$\mathrm{Co}$ & $7.2(0.3)$ & $8.3(7.6-9)$ \\
\hline
\end{tabular}

SRM $1635\left(\mu \mathrm{g} \mathrm{g}^{-1}\right)$

Element Microwave Certified $^{\mathrm{c}}$

\begin{tabular}{lll}
\hline $\mathrm{Pb}$ & $1.5(0.3)$ & $1.9(0.2)$ \\
$\mathrm{Mn}$ & $21.0(0.3)$ & $21.4(1.5)$ \\
$\mathrm{Ni}$ & $1.51(0.31)$ & $1.74(0.1)$ \\
$\mathrm{V}$ & $5.1(0.4)$ & $5.2(0.5)$ \\
$\mathrm{Cu}$ & $3.0(1.0)$ & $3.6(0.3)$ \\
$\mathrm{Zn}$ & $6.8(1.2)$ & $4.7(0.5)$ \\
$\mathrm{As}$ & $<\mathrm{LD}$ & $0.42(0.15)$ \\
$\mathrm{Co}$ & $0.62(0.04)$ & $0.65^{\mathrm{d}}$ \\
\hline
\end{tabular}

a The parentheses values are the standard deviation of 3 determinations $(n=3)$.

b The parentheses values are the confidence intervals.

${ }^{\mathrm{c}}$ For this certified reference material, the parenthesis values are the standard deviation.

d Non-certified value. 


\section{Figures of Merit}

The figures of merit are listed in Table V. The detection limit (LOD) was calculated as three times the standard deviation $(3 \sigma)$ of 10 consecutive measurements of the blank signal divided by the slope of the calibration curve for $0.2 \mathrm{~g}$ of sample in $30 \mathrm{~mL}$ of solution. It should be noted (see Table V) that the correlation coefficients $(r)$ were all above 0.999 in the calibration range investigated. The limits of detection (LOD) of all analytes were lower than the lowest concentrations obtained for each analyte in the suspension.

\section{Analysis of Real Coal Samples}

The proposed methodology was also applied to the analysis of real coal samples obtained from three different coal mines located in the states of Rio Grande do Sul (RS), Paraná (PR), and Santa Catarina (SC) of southern Brazil. The results obtained were also compared with microwave decomposition and are presented in Table VI. Most element concentrations depicted in Table VI show that the values were close for both methods, except for $\mathrm{V}$, repeating the behavior already presented in the analysis of the certified materials. The results obtained for the coals from the three different mines suggest that the sample collected at the Figueira power plant, located in $\mathrm{PR}$, is characterized by relatively high concentrations for some trace elements (As, $\mathrm{Pb}$, and $\mathrm{Zn}$ ) in comparison to coals from RS and SC (44-45). Elements such as As and $\mathrm{Pb}$ are known to have high affinities to pyrite and ferric oxides and, in the case of the coal from Figueira, can be related to the relatively high pyrite contents of the coal (44).
TABLE V

Figures of Merit

\begin{tabular}{|c|c|}
\hline Calibration Curve $^{\mathrm{a}}\left(\mu \mathrm{g} \mathrm{L}^{-1}\right)$ & $\begin{array}{l}\text { As and } \mathrm{Cu}(10-240) \mathrm{Co}(2.5-80) \text {, } \\
\mathrm{Mn} \text { and } \mathrm{Zn}(25-600), \mathrm{Ni}(10-180) \text {, } \\
\mathrm{Pb} \text { and } \mathrm{V} \mathrm{(10-320)}\end{array}$ \\
\hline Correlation Coefficient (r) & $\begin{array}{l}\text { As (0.99959), Co (0.99989), Cu (0.99994), } \\
\text { Mn (0.99997), Ni (0.99962), Pb (0.99938), } \\
\text { V (0.99996), Zn (0.99932) }\end{array}$ \\
\hline $\operatorname{LOD}^{\mathrm{b}}\left(\mu \mathrm{g} \mathrm{g}^{-1}\right)$ & $\begin{array}{l}\text { As (1.0), Co (0.1), Cu (0.1), Mn (0.01), } \\
\mathrm{Ni}(0.2), \mathrm{Pb}(1.1), \mathrm{V}(0.3), \mathrm{Zn}(0.2)\end{array}$ \\
\hline
\end{tabular}

${ }^{a}$ Standard solutions in $\mathrm{HNO}_{3}$ 15\% (v/v).

${ }^{\mathrm{b}} 0.2 \mathrm{~g}$ in $30 \mathrm{~mL}$ of solution.

TABLE VI

Analysis of Real Coal Samples From the States of the South of Brazil (Rio Grande do Sul, Santa Catarina, and Parana) by ICP-OES After Acid Extraction and Microwave Decomposition

\begin{tabular}{lcl}
\hline \multicolumn{3}{l}{ RS Rio Grande do Sul, Brazil $\left(\mu \mathrm{g} \mathrm{g}^{-1}\right)$} \\
\hline $\mathrm{Element}$ & Acid Extraction & Microwave \\
\hline $\mathrm{Pb}$ & $10.0(0.4)^{\mathrm{a}}$ & $9.0(0.3)^{\mathrm{a}}$ \\
$\mathrm{Mn}$ & $126(2)$ & $124(1)$ \\
$\mathrm{Ni}$ & $7.1(0.1)$ & $9.2(1.0)$ \\
$\mathrm{V}$ & $29(2)$ & $48(2)$ \\
$\mathrm{Cu}$ & $9.2(0.1)$ & $10.0(1.0)$ \\
$\mathrm{Zn}$ & $44(2)$ & $51(2)$ \\
$\mathrm{As}$ & $11.0(2.0)$ & $13.2(1.0)$ \\
$\mathrm{Co}$ & $6.3(0.2)$ & $7.1(1.0)$ \\
$\mathrm{SC}=$ Santa Catarina, Brazil $\left.(\mu \mathrm{g} \mathrm{g})^{-1}\right)$ & \\
$\mathrm{Elemen}$ & Acid Extraction & Microwave \\
$\mathrm{Pb}$ & $11.3(0.3)$ & $9.3(0.3)$ \\
$\mathrm{Mn}$ & $66(1)$ & $70(2)$ \\
$\mathrm{Ni}$ & $12.0(1.0)$ & $15.2(0.3)$ \\
$\mathrm{V}$ & $23.0(0.2)$ & $95.0(2.0)$ \\
$\mathrm{Cu}$ & $10.1(0.4)$ & $11.1(0.3)$ \\
$\mathrm{Zn}$ & $99(1)$ & $107(2)$ \\
$\mathrm{As}$ & $11.1(1.0)$ & $10.1(0.1)$ \\
$\mathrm{Co}$ & $4.3(0.2)$ & $6.3(0.2)$ \\
\hline
\end{tabular}

\begin{tabular}{|c|c|c|}
\hline \multicolumn{3}{|c|}{ PR = Parana, Brazil $\left(\mu g g^{-1}\right)$} \\
\hline Element & Acid Extraction & Microwave \\
\hline $\mathrm{Pb}$ & $97(2)$ & $85(4)$ \\
\hline Mn & $122(2)$ & $115(12)$ \\
\hline $\mathrm{Ni}$ & $19(1)$ & $20.0(0.4)$ \\
\hline $\mathbf{V}$ & $33(2)$ & $80(3)$ \\
\hline $\mathrm{Cu}$ & $12.3(0.2)$ & $12(1)$ \\
\hline $\mathrm{Zn}$ & $619(31)$ & $601(33)$ \\
\hline As & $493(11)$ & $487(18)$ \\
\hline $\mathrm{Co}$ & $6.0(0.0)$ & $7(1)$ \\
\hline
\end{tabular}

${ }^{a}$ The parentheses values are the standard deviation of 3 determinations $(n=3)$. 


\section{CONCLUSION}

The methodology, developed using acid extraction assisted by ultrasound, using only nitric acid as extractor and heating, showed to be suitable for the determination of $\mathrm{As}, \mathrm{Co}, \mathrm{Cu}, \mathrm{Mn}, \mathrm{Ni}, \mathrm{Pb}$, and $\mathrm{Zn}$ in coal samples by ICP-OES with external calibration. The proposed method showed good precision with a relative standard deviation ranging from 0.4 to $22.8 \%$. Several factors influenced the extraction of these elements, such as extraction time in $\mathrm{HNO}_{3}$, particle size, and heating. Sample preparation was relatively simple, especially when compared with the conventional decomposition methods. It proved to be advantageous since, in this case, the manipulation of corrosive acids, risks related to safety, excessive sample manipulation, high reagent consumption, as well as higher energy costs, were minimized. Nevertheless, for V, accurate results were only obtained when microwave digestion was used to decompose the samples.

\section{ACKNOWLEDGMENT}

The authors are grateful to CAPES for financial support.

Received March 5, 2013.

\section{REFERENCES}

1. H.H. Schobert, Coal, the Energy Source of the Past and Future; American Chemical Society: Washington, DC, 1987, p 2.

2. D.J. Swaine, F. Goodarzi, Environmental Aspects of Trace Elements in Coal; Vol. 2, Kluwer Academic Publishers, Dordrecht, The Netherlands, 1995, p 5.

3. Y.H. Xu, A. Iwashita, T. Nakajima, H. Yamashita, H. Takanashi, and A. Ohki, Talanta 66, 58 (2005).

4. K.L. Laban and B.P. Atkin, International Journal of Coal Geology, 41, 351 (1999)

5. P.F. Nelson, P. Shah, V. Strezov, B. Halliburton, and J.N. Carras, Fuel 89, 810 (2010).

6. M.A.B. Pougnet and L.C.S. Haraldsen, Afr. J. Chem. 45, 50 (1992).

7. S.D. Çekiç, H. Filik, and R. Apak, Anal. Chim. Acta 505, 15 (2004).

8. L. Bianchin, D. Nadvorny, A.F. Silva, M.G.R. Vale, M.M. da Silva, W.N.L. dos Santos, S.L.C Ferreira, B. Welz, and U. Heitmann, Microchem. Journal 82, 174 (2006).

9. A.F. da Silva, D.L.G. Borges, F.G. Lepri, B. Welz, A.J. Curtius, and U. Heitmann, Anal. Bioanal. Chem. 382, 1835 (2005).

10. M.A. Vieira, B. Welz, and A.J. Curtius, Rev. Spectrochim. Acta B. 57, 2057 (2002).

11. I. Rodushkin, M.D. Axelsson, and E. Burman, Talanta 51, 743 (2000).

12. J. Wang, T. Nakazato, K. Sakanishi, O. Yamada, H. Tao, and I. Saito, Anal. Chem. Acta 514, 115 (2004).

13. S.M. Maia, J.B.B. da Silva, A.J. Curtius, and B. Welz, J. Anal. At. Spectrom. 15, 1081 (2000).

14. Y. Zhang, Z. Jiang, and B. Hu, Rapid Commun. Mass Spectrom. 20, 2091 (2006).

15. C.F. Petry, D. Pozebon, and F.R.S. Bentlin, At. Spectrosc. 26, 19 (2005).

16. J. Nölte, ICP Emission Spectrometry; A Pratical Guide; Wiley-VCH, Weinheim, Germany (2003), 267 p. 3 .

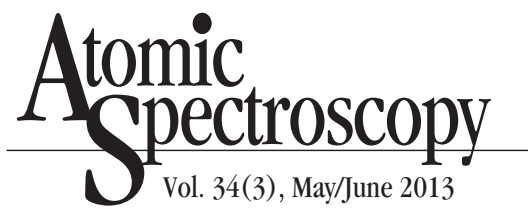

17. H. Lachas, R. Richaud, K.E. Jarvis, A.A. Herod, D.R. Dugwell, and R. Kandiyoti, The Analyst 124, 177 (1999).

18. O.W. Lau, L. Lam, and S. F. Luk, Talanta 51, 1009 (2000).

19. F.J. Krug, Métodos de Decomposição de Amostras; In: Workshop Sobre preparo de Amostras: VI. 2006. Universidade Federal de Santa Maria, Santa Maria. RS.

20. H.G.M. Parry and L. Ebdon, Anal. Proceedings 25, 69 (1988).

21. M.A. Vieira, A.S. Ribeiro, and A.J. Curtius, Microchem. Journal 82, 127 (2006).

22. S.M. Maia, D. Pozebon, and A.J. Curtius, J. Anal. At. Spectrom. 18, 330 (2003).

23. L. Ebdon, M. Foulkes, and K. Sutton, J. Anal. At. Spectrom. 12, 213 (1997).

24. C. Bendicho and M.T.C. de LoosVollebregt, J. Anal. At. Spectrom. 6, 353 (1991).

25. N. J. Miller-Ihli, J. Anal. At. Spectrom. 9, 1129 (1994).

26. P. Bermejo-Barrera, M.C. BarcielaAlonso, J. Moreda-Piñeiro, C. González-Sixto, and A. BermejoBarrera, Spectrochim. Acta, Part B, 51, 1235 (1996).

27. D.T. Takuwa, G. Sawula, G. Wibetoe, and W. Lund, J. Anal. At. Spectrom. 12, 849 (1997).

28. N. J. Miller-Ihli, Fresenius' J. Anal. Chem. 345, 482 (1993).

29. L. Ebdon, M.E. Foulkes, H.G.M. Parry, and C.T. Tye, J. Anal. At. Spectrom. 3, 753 (1988).

30. D.C. Grégoire, N.J. Miller-Ihli, and R.E. Sturgeon, J. Anal. At. Spectrom. 9, 605 (1994).

31. I. López-García, M. Sánchez-Merlos, and M. Hernández-Córdoba, Spectrochim. Acta, Part B, 52, 2085 (1997).

32. J. Ruiz-Jiménez, J.L. Luque Garcia, and M.D. Luque de Castro, Anal. Chim. Acta 480, 231 (2003).

33. S. Río-Segade and C. Bendicho, J. At. Spectrom. 14, 1907 (1999). 
34. C.P. Hanna, J.F. Tyson, and S. McIntosh, Anal. Chem. 65, 653 (1993).

35. J.L. Capelo, I. Lavilla, and C. Bendicho, Anal. Chem. 72, 4979 (2000).

36. A.S. Ribeiro, M.A. Vieira, and A.J. Curtius, J. Braz. Chem. Soc. 15, 825 (2004).

37. A. Collasiol, D. Pozebon, and S.M. Maia, Anal. Chim. Acta 518, 157 (2004).

38. A. Ilander and A. Väisänen, Anal. Chim. Acta 602, 195 (2007).

39. F.V.M. Pontes, B.A. de O. Mendes, E.M.F. de Souza, F.N. Ferreira, L.I.D. da Silva, M.C. Carneiro, M.I.C. Monteiro, M.D. de Almeida, A.A. Neto, and D.S. Vaitsman, Anal. Chim. Acta 659, 55 (2010).

40. L.G. Trindade, C.P. Franchi, S.M. Maia, D. Pozebon, and E.L. Seibert. Investigação de metodologia alternativa para a determinação de elementos em nível de traços em carvão pela técnica de ICP OES, In: Encontro Nacional de Química Analítica. 13, ENQA, 2005, Niterói, Brasil.

41. K.E. Jarvis, A.L. Gray, and R.S. Houk, Handbook of Inductively Coupled Plasma Mass Spectrometry, 1st ed., Black \& Son Ltd., London, 1992, p. 51, 81.

42. E.M.M. Flores, B. Welz, and A.J. Curtius, Spectrochim. Acta B, 56, 1605 (2001).

43. J.C. Miller and J.N. Miller, Statistics for Analytical Chemistry, 2nd ed., E. Horwood, London, England, 1988, p. 40.

44. J.H. Levandowski and W. Kalkreuth, International Journal of Coal Geology 77, 269 (2009).

45. D. Pozebon, F. dos S. Depoi, and W. Kalkreuth, International Journal of Coal Geology 76, 227 (2008). 